\title{
DETECTION SINGLE NUCLEOTIDE POLYMORPHISMS IN UROMODULIN PROMOTER REGION ASSOCIATED WITH RENAL DISEASES USING SINGLE-STRAND CONFORMATION POLYMORPHISM-POLYMERASE CHAIN POLYMORPHISMS TECHNIQUE
}

\author{
ZAHRAA ISAM ${ }^{1}$, RABAB OMRAN ${ }^{2 *}$, AMMAD HASSAN MAHMOOD ${ }^{3}$ \\ ${ }^{1}$ Department of Biology, College of Science, University of Babylon, Al-Hillah City, Babel, Iraq. ${ }^{2}$ Department of Biology, College of Science, \\ University of Babylon, Al-Hillah City, Babel, Iraq. ${ }^{3}$ Department of Urology, College of Medicine, University of Babylon, Consultant Urologist \\ in Hilla Teaching Hospital, Al-Hillah City, Babel, Iraq. Email: omranaljelawi@gmail.com
}

Received: 17 August 2017, Revised and Accepted: 10 October 2017

ABSTRACT

Objective: The uromodulin, a glycoprotein, expressed and secreted by epithelial kidney cells lining the thick ascending limb of the Henle's loop. It is encoded by the UMOD gene in humans. Our objective was to analyze single nucleotide polymorphisms (SNPs) in the UMOD promoter region in patients with chronic kidney disease (CKD) and end-stage renal disease (ESRD).

Methods: The blood samples were collected from 100 patients with CKD (50) and ESRD (50), who admitted at Merjan Teaching Hospital in Babylon Province, Iraq (February-July 2016). In addition, 50 blood samples of healthy control. The SNPs of UMOD promoter region was investigated using single-strand conformation polymorphism-polymerase chain polymorphisms (SSCP-PCR) and DNA sequencing techniques.

Results: UOMD promoter region polymorphisms using PCR-SSCP and sequencing DNA appeared three different conformational haplotypes, including $\mathrm{A} \backslash \mathrm{G} 49$ haplotype (5 bands), $\mathrm{A} \backslash \mathrm{G} 49$ and $\mathrm{C} \backslash \mathrm{A} 247$ haplotype (5 bands), and $\mathrm{C} \backslash \mathrm{G} 45$ and $\mathrm{A} \backslash \mathrm{G} 49$ haplotype ( 6 bands) distributed among CKD and ESRD cases, due to the presence of three SNPs. There was no association between band numbers of PCR-SSCP with ESRD and CKD compared with a control group.

Conclusion: SSCP-PCR is a good screening method to detect genetic variations in an uromodulin promoter region.

Keywords: Chronic kidney disease, End-stage renal disease, UMOD-promoter region, SNPs, Single-strand conformation polymorphism-polymerase chain polymorphisms.

(c) 2018 The Authors. Published by Innovare Academic Sciences Pvt Ltd. This is an open access article under the CC BY license (http://creativecommons. org/licenses/by/4. 0/) DOI: http://dx.doi.org/10.22159/ajpcr.2018.v11i1.22063

\section{INTRODUCTION}

Uromodulin is an integral glycoprotein with the epithelial kidney lining cell membrane by glycophosphatidylinositol (GPI)-anchored. It

is completely produced by the thick ascending limb (TAL) of the Henle's loop and excreted in ordinary urine. In human, the uromodulin is encoded by the UMOD gene, which composed of eleven exons located on chromosome 16p12.3 [1,2]. The primary structure of the polypeptide chain which containing 640 amino acids (aa) with

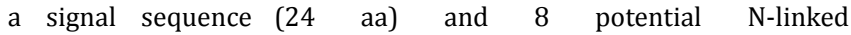
glycosylation sites [3]. Sequence homology revealed that the protein is may contain $\mathrm{N}$-terminal signal sequence; three epidermal growth factor (EGF)-like domains, the second and third of EGF-like domains contain a calcium-binding motif; a central domain of eight cysteines (D8C) within a cysteine-rich region; a zona pellucida domain is essential for the extracellular protein polymerization into helical filaments; and GPI-anchoring site for integrating the protein with the cell membrane [4]. A key structural feature of the uromodulin is rich cysteine amino acid content (48 cysteines) for creating 24 intrachain disulfide bridges, which critical to construct the correct structure [3]. The biosynthesis of this protein and modification occurs in the rough endoplasmic reticulum (RER) of the TAL cells of the kidney. The protein precursor $(84 \mathrm{kDa})$ is modified by adding the carbohydrate moiety and GPI anchor-linked molecule to become mature macromolecule with a noticeable mass of $97 \mathrm{kDa}$. The mature macromolecule once transports across the plasma membrane, cleaved and the free parts secreted with the tubular fluid [3,4]. The uromodulin is existing in urine as a big aggregates or polymeric of glycoprotein, and their molecular weight reached to millions of Daltons. The rate-limiting step in the uromodulin maturation is that the pathway inside the RER, in all probability as a result of the tertiary structure forming [1].
Inspite of over 50 years of uromodulin analysis that focuses on its physiological roles has remained elusive, causing a gradual decline of the research. Recently, highlighted heredity investigations that proved the importance of this protein, since the uromodulin mutations were implicated in dominant tubulointerstitial viscus ill health [2,5]. Several genome-wide association studies (GWASs) investigated a lot of UMOD genetic risk loci (such as rs12917707, rs6497476, and rs4293393) were concerned with estimated glomerular filtration rate (eGFR) related to chronic kidney disease (CKD) or upset [6,7]. In 2009, the single-nucleotide polymorphisms (SNPs) in the UMOD gene were investigated among a big cohort of patients suffering from CKD and found that these SNPs may be implicated to the genetic standing in endstage renal disease (ESRD) [8]. SNPs are single-nucleotide variations that have arisen randomly over time in the human genome, and it is mostly occurring in noncoding regions $[7,8]$. The aim of the study was to analyzes single-nucleotide polymorphism (SNP) in the promoter region of the UMOD gene in patients suffering from CKD and ESRD using polymerase chain polymorphisms-single-strand conformation polymorphism (PCR-SSCP) technique.

\section{METHODS}

\section{Sampling}

This was a case study conducted in the Biotechnology and Genetic Engineering Laboratory, Department of Biology, College of Science, University of Babylon, Iraq. The blood samples (150) were collected from patients suffering from CKD (50) and ESRD (50), in addition to healthy persons (50) as a control group. Blood samples were taken from out-and in-patients who admitted to Merjan Teaching Hospital (Dialysis Center), Babylon Province, from February to July 2016. All the participants were evaluated by a certified physician, who was also 
responsible for getting the most analytical and clinical values such as urea and creatinine concentrations. The patients with hepatitis were excluded from the study.

\section{Genotyping using PCR-SSCP technique}

The genotyping of the studied groups were performed using the SSCP-PCR technique after DNA extraction from blood samples. DNA was extracted from blood samples and purified using extraction and purification kit (Geneaid company - UK).

The targeted sites of the UMOD promoter regions were amplified using design-specific primers (Bioneer, IDTDNA

USA). Forward: 5'-GGGGATCTTCTCCCTTGGC-3'; Reverse: 5' - CAACCCACGTCACAGGGAAG-3'

PCR was carried out in the reaction mixture containing $1 \mu \mathrm{l}$ from forward and reverse primers, $12.5 \mu \mathrm{l}$ of Green Master Mix, and $3 \mu \mathrm{l}$ of genomic DNA, and the volume of reaction was completed up to $20 \mu \mathrm{l}$ by adding $2.5 \mu \mathrm{l}$ of the nuclease-free water. Amplification was carried out in a TRIO Thermal Cycler (Biometra, Germany) programed for 2 min pre-denaturation at $94^{\circ} \mathrm{C} ; 30$ cycles, $5 \mathrm{~min}$ at $94^{\circ} \mathrm{C}$ (DNA denaturation), $1 \mathrm{~min}$ at $61^{\circ} \mathrm{C}$ (annealing), and $1 \mathrm{~min}$ at $72^{\circ} \mathrm{C}$ (extended); and a final extension of $5 \mathrm{~min}$. PCR products were electrophorezed using gel electrophoresis (Cleaver Scientific - UK) in 1\% agarose at $75 \mathrm{~V}$ for 1 hand visualized by ethidium bromide. Photos were taken using gel documentation system (Cleaver Scientific - UK).

After the amplification of the target sequence, SSCP was performed using polyacrylamide gel (PAG) electrophoresis throughout the following steps:

1. The $8 \%$ PAG was prepared and poured into the medium-casting tray $(20 \times 20 \times 0.1 \mathrm{~cm} ; \mathrm{H} \times \mathrm{W} \times \mathrm{T})$. The PAG (total volume $40 \mathrm{ml})$ composed of $8 \mathrm{ml}$ of $40 \%$ acrylamide/bisacrylamide, $4 \mathrm{ml}$ of $10 \times$ TBE, $2.8 \mathrm{ml}$ of glycerol, $40 \mu \mathrm{l}$ of TEMED, $400 \mu \mathrm{l}$ of $10 \%$ ammonium persulfate, and $24.8 \mathrm{ml}$ of deionized water.

2. During the gel solidified, the DNA samples were prepared by mixing $10 \mu \mathrm{l}$ of PCR products with $10 \mu \mathrm{l}$ of $2 \times$ SSCP loading dye in Eppendorf tubes separately. Then, they incubated in a water bath at $95^{\circ} \mathrm{C}$ for $7 \mathrm{~min}$. Subsequently, the mixtures immediately were placed in an ice bath for $5 \mathrm{~min}$.

3. The samples were loaded into $8 \%$ PAG and migrated using vertical electrophoresis unite (Cleaver Scientific - UK) at $200 \mathrm{~V}, 35 \mathrm{~mA}$, and $6 \mathrm{~W}$ for 180 min or until SSCP tracking dye reaches the bottom of the gel.

4. 4. The gels visualized by ethidium bromide. Photos were taken using gel documentation system (EBOXCX - UK).

\section{Sequencing of amplified DNA fragment}

The amplified fragments were purified using the protocol suggested by Macrogen sequencing company (Macrogen - Korea), and then, they were sequenced using each primer pair. The sequences of the gene fragments analyzed were aligned by multiple sequence alignment program, according to Bio-edit, with the sequences published in the Gen Bank database taken as a reference to identify the polymorphisms.

\section{Statistical analysis}

Statistical analysis was carried out using SPSS version 16 , and $p \leq 0.05$ was considered statistically significant.

\section{RESULTS}

The cases of the study involved 150 samples divided into three groups: Two patient groups, including chronic and ESRD (each of them containing 50 patients) and healthy control groups (50). The study included female and male as a percentage $50 \%$ for both at the age ranged between 11 and 80 years. Furthermore, the percentage of hypertension was present in $43.33 \%$, while in non-hypertension group was $56.665 \%$. In addition, the percentage of patients with diabetes was $10 \%$, whereas non-diabetic patients were $90 \%$. Finally, the percentage of smoker patients was $33.33 \%$, whereas the nonsmoker patients was $66.66 \%$.
The results revealed that the CKD and ESRD groups had high significant differences $(p \leq 0.05)$ of urea, creatinine, and calcium levels in comparison with control groups. These levels significantly increased $(\mathrm{p} \leq 0.05)$ in female and male patient group compared with control groups.

The genomic DNA was extracted from the blood samples and electrically migrated in 1\% agarose, $75 \mathrm{~V}, 20 \mathrm{~mA}$ for $1 \mathrm{~h}$, (Fig. 1). Fig. 2 showed the amplification product of the UOMD promoter region. Fig. 3 showed PAG electrophoresis of SSCP-PCR conformational haplotypes of the amplified products (317 bp) of promoter region of $U O M D$ gene.

The results of UOMD promoter region polymorphisms revealed that the presence of four different conformational haplotypes appeared in patient and control groups, including haplotype with 4 bands, two haplotype patterns ( $\mathrm{a}$ and $\mathrm{b}$ ) containing 5 bands and haplotype with 6 bands. Whereas the sequencing results (Fig. 4) showed the presence of three SNPs determined the haplotypes of the UOMD promoter region

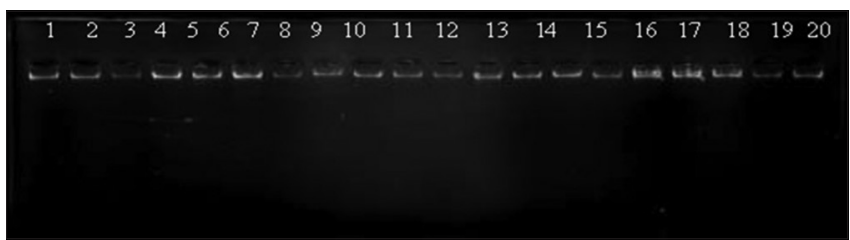

Fig. 1: The electrophoresis pattern of genomic DNA extracted from blood of patients with chronic kidney disease and end-stage renal disease as well as healthy control groups. Lane 1-20 refers to extracted DNA from blood samples; electrophoresis conditions: $1 \%$ agarose, $75 \mathrm{~V}, 20 \mathrm{~mA}$ for $1 \mathrm{~h}$ (10 $\mu \mathrm{l}$ in each well).

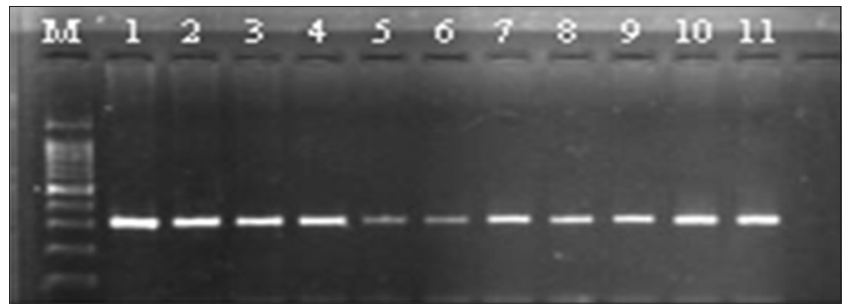

Fig. 2: Agarose gel electrophoresis of amplified products of UOMD promoter region of patients with chronic kidney disease and end-stage renal disease and healthy control groups. M: DNA size marker; lane 1-11 refers to the patterns of amplified products of $U M O D$ promoter region ( $317 \mathrm{bp}$ ). Electrophoresis conditions:

$1 \%$ agarose, $75 \mathrm{~V}, 20 \mathrm{~mA}$ for $120 \mathrm{~min}$. The band staining with ethidium bromide

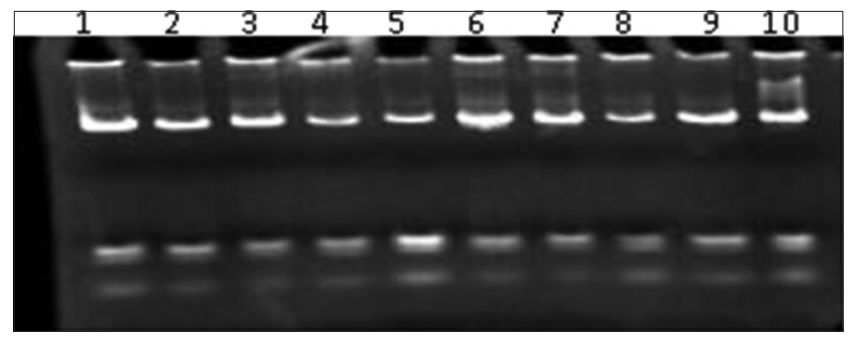

Fig. 3: DNA polymorphisms of the UOMD promoter region of patients chronic kidney disease (CKD), end-stage renal disease (ESRD) and control using polymerase chain polymorphismssingle-strand conformation polymorphism technique. Lanes 2 and 9 represent the control group; lanes $1,3-8$, and 10 represent the groups of patients (CKD and ESRD). Electrophoresis conditions: $8 \%$ polyacrylamide, power applied: $200 \mathrm{~V}-100 \mathrm{~mA}$, for $180 \mathrm{~min}$. The DNA bands stained using ethidium bromide 
depending on Primer3 plus reference sequences (ID: AY061638.1). These SNPs were $C \backslash G 45, A \backslash G 49$, and $C \backslash A 247$ that distributed among CKD and ESRD patients. According to PCR-SSCP and sequencing results, there were three conformational haplotypes appeared among patient groups in comparison with control group (4-bands haplotype) (Fig. 5). There was $A \backslash G 49$ conformational haplotype, which appeared 5 bands (3-7) in ESRD and CKD cases. The second was A $\backslash \mathrm{G} 49$ and C\A 247 conformation haplotypes, which showed the presence of 5 bands $(2,4-7)$ distributed in ESRD cases. The third was $C \backslash G 45$ and $A \backslash G 49$ conformational haplotype, which revealed the presence of 6 bands $(1,3-7)$ in ESRD cases. Furthermore, the results showed that there was no association between numbers of bands of PCR-SSCP with ESRD and CKD that indicates the SNPs were associated with both CKD and ESRD.

Table 3 refers to the present significant differences $(p \leq 0.05)$ in the serum levels of urea, creatinine, and calcium among PCR-SSCP polymorphisms of the UMOD gene in ESRD group, while there are no significant differences in the concentrations in CKD group.

\section{DISCUSSION}

The consequences of the promoter region of the uromodulin encoding gene illustrated that four different haplotypes according to the number and location of the bands in the gel. These conformations including 4, 5 (two types $5 \mathrm{a}$ and $5 \mathrm{~b}$ ), and 6 bands. These variable conformations ( $5 \mathrm{a}, 5 \mathrm{~b}$, and 6 bands) may be due to the presence of three SNPs within the studied region which determined by the DNA sequencing results, whereas the haplotype with 4 bands in patient groups and control was not contained the detected SNPs, that may indicate the patient group containing other SNPs in other UMOD regions or other related genes because of the renal disease is multi-factorial. Conversely, these SNPs were detected between two groups of renal disease; in ESRD patient

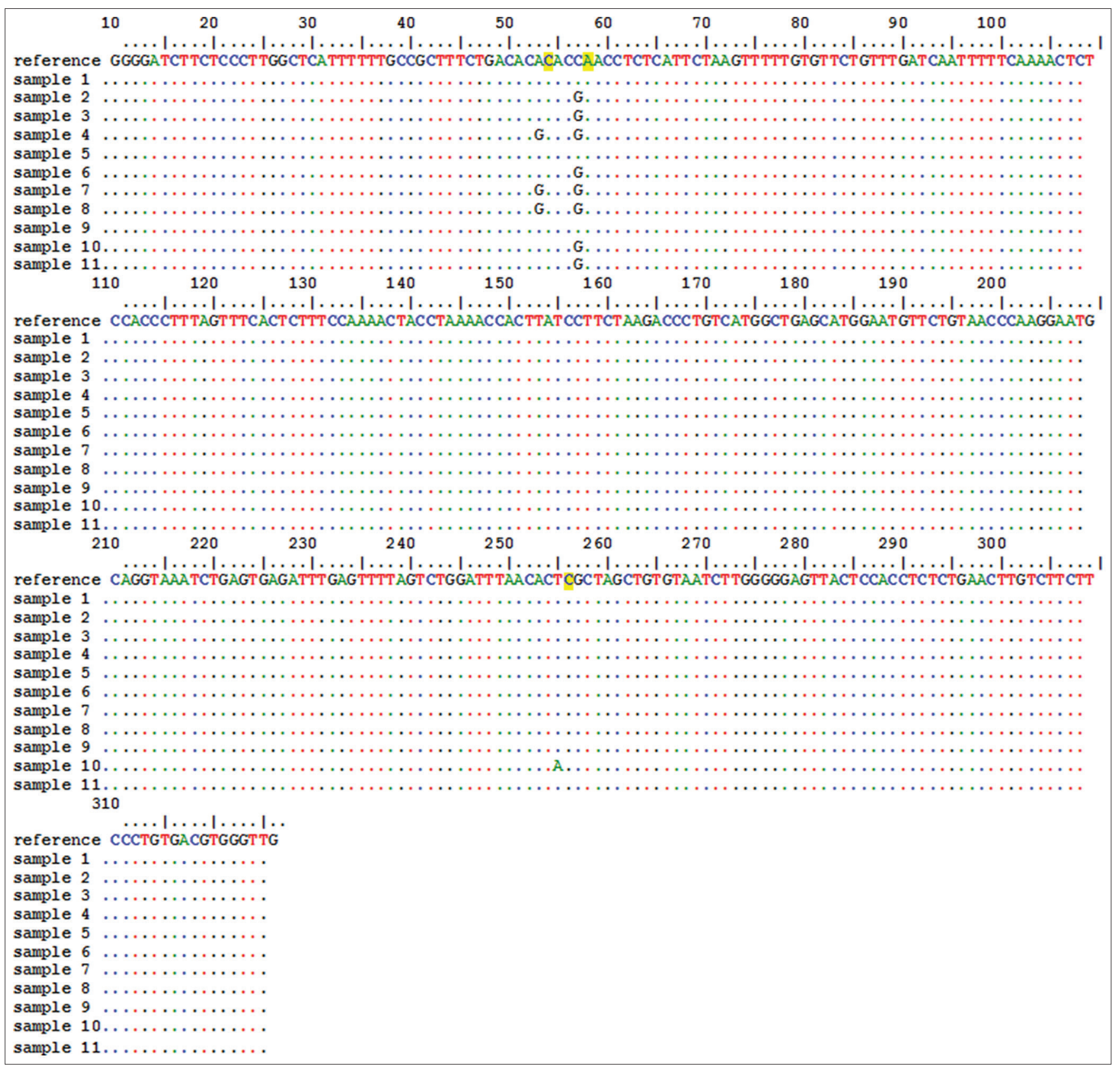

Fig. 4: Sequences alignment ID: AY061638.1 results for Homo sapiens, UOMD gene promoter region by Bio Edit program version 7.2.5 Samples $(1,5$, and 9$)$ refer to control, samples $(2,3,4,6,7,8,10$, and 11) refer to patients, including end-stage renal disease $(2,3,8$, and 11 samples) and chronic kidney disease $(4,6,7$, and 10 samples $)$ 
Table 1: PCR-SSCP haplotype distribution of UMOD promoter region by the number of bands and their association with ESRD and control groups

\begin{tabular}{|c|c|c|c|c|c|}
\hline Conformational haplotypes & ESRD group number (\%) & Control group number $(\%)$ & $p$ value & OR & $95 \% \mathrm{CI}$ \\
\hline 4 bands $^{\mathrm{a}}$ & $18(36)$ & $23(46)$ & 0.25 & 1.47 & $0.28-1.61$ \\
\hline 5 bands & $22(44)$ & $19(38)$ & & & \\
\hline 6 bands & $10(20)$ & $8(16)$ & 0.29 & 1.59 & $0.52-4.87$ \\
\hline 5 bands $^{\mathrm{a}}$ & $22(44)$ & $19(38)$ & 0.65 & 1.07 & $0.35-3.28$ \\
\hline 6 bands & $10(20)$ & $8(16)$ & & & \\
\hline Total number & 50 & 50 & & & \\
\hline
\end{tabular}

aReference; *p $\leq 0.05$; OR=95\% CI; ESRD: End-stage renal disease, PCR-SSCP: Polymerase chain polymorphisms-single-strand conformation polymorphism, OR: Odds ratio, CI: Confidence interval

Table 2: PCR-SSCP haplotype distribution of UMOD promoter region by the number of bands and their association with CKD and control groups

\begin{tabular}{|c|c|c|c|c|c|}
\hline Conformational haplotypes & CKD group number (\%) & Control group number $(\%)$ & p value & OR & $95 \% \mathrm{CI}$ \\
\hline 4 bands $^{a}$ & $19(38)$ & $23(46)$ & 0.50 & 1.33 & $0.46-2.61$ \\
\hline 5 bands & $21(42)$ & $19(38)$ & & & \\
\hline 6 bands & $10(20)$ & $8(16)$ & 0.32 & 1.51 & $0.49-4.59$ \\
\hline 5 bands $^{\mathrm{a}}$ & $21(42)$ & $19(38)$ & 0.52 & 1.13 & $0.37-3.45$ \\
\hline 6 bands & $10(20)$ & $8(16)$ & & & \\
\hline Total number & 50 & 50 & & & \\
\hline
\end{tabular}

${ }^{a}$ Reference; * $\leq 0.05$; OR=95\% CI; CDK: Chronic kidney disease, ESRD: End-stage renal disease, PCR-SSCP: Polymerase chain polymorphisms-single-strand conformation polymorphism, OR: Odds ratio, CI: Confidence interval

Table 3: The association of PCR-SSCP polymorphisms of UOMD gene in renal disease groups with physiological parameter

\begin{tabular}{|c|c|c|c|}
\hline \multirow{2}{*}{$\begin{array}{l}\text { PCR-SSCP haplotypes band } \\
\text { number (n) }\end{array}$} & \multicolumn{3}{|l|}{ Mean \pm SE } \\
\hline & Urea (ng/ml) & Creatinine $(\mathrm{ng} / \mathrm{ml})$ & Calcium (ng/ml) \\
\hline \multicolumn{4}{|l|}{ CKD } \\
\hline $4(\mathrm{n}=18)$ & $26.45 \pm 1.68$ & $511.55 \pm 28.64$ & $2.25 \pm 0.15$ \\
\hline $5(\mathrm{n}=22)$ & $25.34 \pm 1.78$ & $696.94 \pm 43.87$ & $2.23 \pm 0.08$ \\
\hline $6(\mathrm{n}=10)$ & $27.96 \pm 1.36$ & $597.49 \pm 72.19$ & $2.04 \pm 0.14$ \\
\hline $\mathrm{p}$ value & 0.62 & 0.01 & 0.55 \\
\hline \multicolumn{4}{|l|}{ ESRD } \\
\hline $4(n=19)$ & $26.39 \pm 1.82$ & $579.46 \pm 40.24$ & $1.89 \pm 0.06$ \\
\hline $5(\mathrm{n}=21)$ & 24.421 .20 & $685.51 \pm 40.61$ & $1.87 \pm 0.12$ \\
\hline $6(n=10)$ & $21.24 \pm 2.72$ & $521.19 \pm 76.86$ & $1.80 \pm 0.06$ \\
\hline $\mathrm{p}$ value & 0.19 & 0.069 & 0.84 \\
\hline
\end{tabular}

n: Patient number, CKD: Chronic kidney disease, ESRD: End-stage renal disease, $\mathrm{p} \leq 0.05$. The results represent as mean \pm SE (standard error), PCR-SSCP: Polymerase chain polymorphisms-single-strand conformation polymorphism

groups, the results indicate that there was no association between 4,5 , and 6 bands and CKD as compared with a control group. UMOD gene is transcribed utterly within the urinary organ as disclosed by Northern blot analysis. The transcription specificity of $U M O D$ is about by its promoter sequence. The biological effectiveness of uromodulin is still rather mysterious, and it may have ability to conserve water/electrolyte balance inside the TAL depending on its gelification and physicochemical characteristics. In addition, it has protective effects against urinary tract infections (UTI) in Umod knockout mice [9]. This function is due to the ability of the uromodulin through its rich-mannose moiety to bind with the fimbria of bacteria such as Escherichia coli [10]

GWASs have successfully identified genomic loci comprising susceptibility variations related to the risk of complex characters and markers of renal function [11]. Particularly, common variants in the uromodulin encoding gene have been related to the risk of CKD, eGFR, and other complex characters, such as kidney stones and hypertension. One of the first GWASs on CKD applied on 20000 participants of European ancestry from unselected, populationbased groups from the CHARGE association, investigated a high SNP (rs12917707) placed 3.4 upstream of uromodulin encoding gene [12]. However, the rs 12917707 variant of $U M O D$ was related to renal function indices which depending on the serum cystatin $\mathrm{C}$ and creatinine. This variant related to both higher eGFRcys and eGFRcreat and lower risk of the developing CKD. In line with a defensive result. As inevitable, the variants describe higher than make a case for a tiny, low shear (typically, lower than 1\%) of the variation in eGFRcrea. Notably, there was no significant relationship between rs12917707 and hyperuricemia or arthritis [7].

Depending on the finding of Köttgen [11] which revealed that the SNP rs4293393 positioned at $300 \mathrm{bp}$ upstream of the uromodulin encoding gene, is related to increasing a risk of CKD and raised serum creatinine (sCreat) in the Icelandic population. The rs4293393 variation was additionally connected with uric acid levels increasing and amplified risk of arthritis, a distinction with a lower danger of creation of calcium- containing urinary organ stones within the Icelandic population. The relationship between the rs4293393 and rs12917707 variants with creatinine levels increasing was definitely in a meta-analysis of five Europeans isolates (EUROSPAN) and at intervals of the large European cluster [12].

\section{CONCLUSION}

SSCP-PCR is a good screening method to detect genetic variations in an uromodulin promoter region. 


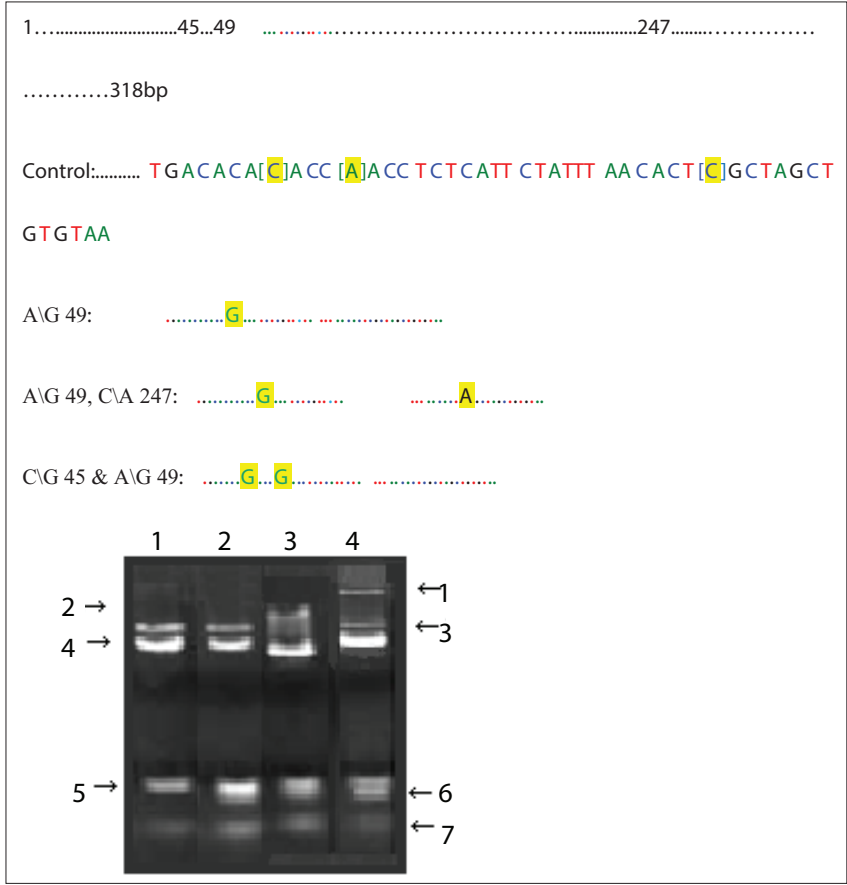

Fig. 5: Association of PCR-SSCP conformations and DNA-sequences of UMOD promoter region in patients with CKD and ESRD. Lane 1: Control conformation; 4 bands $(3,4,5$, and 7$)$ of samples 2,9 , and 5. Lane 2: $A \backslash G 49$ conformation (a); 5 bands $(3,4,5,6$, and 7$)$ of samples of ESRD (1) and CKD (4, 8, and 11). Lane 3: A G 49 and C $\backslash A 247$ conformation (b); 5 bands $(2,4,5,6$, and 7) of sample 10 of ESRD. Lane 4: $C \backslash G 45$ and $A \backslash G 49$ conformation; 6 bands $(1,3$, $4,5,6$, and 7) (Samples $3 \& 6$ of \&7 of ESRD)

\section{ACKNOWLEDGMENT}

The authors are thankful to College of Science, Babylon University and Dialysis unit at Morgan Hospital in Babylon Province and the faculties for providing facilities needed for our work. The authors appreciate the agreements of patients and cooperation to provide the blood samples.

\section{REFERENCES}

1. Rampoldi L, Scolari F, Amoroso A, Ghiggeri G, Devuyst O. The rediscovery of uromodulin (Tamm-Horsfall protein): From tubulointerstitial nephropathy to chronic kidney disease. Kidney Int 2011;80:338-47.

2. Dahan K, Devuyst O, Smaers M, Vertommen D, Loute G, Poux JM, et al. A cluster of mutations in the UMOD gene causes familial juvenile hyperuricemic nephropathy with abnormal expression of uromodulin. J Am Soc Nephrol 2003;14:2883-93.

3. Sumitra K, Pragasam V, Sakthivel R, Kalaiselvi P, Varalakshmi P. Beneficial effect of Vitamin E supplementation on the biochemical and kinetic properties of Tamm-Horsfall glycoprotein in hypertensive and hyperoxaluric patients. Nephrol Dial Transplant 2005;20:1407-15.

4. Scolari F, Izzi C, Ghiggeri GM. Uromodulin: From monogenic to modification diseases. Nephrol Dial Transplant 2015;30:1250-6.

5. Trudu M, Janas S, Lanzani C, Debaix H, Schaeffer C, Ikehata M, et al. Common noncoding umod gene variants induce salt-sensitive hypertension and kidney damage by increasing uromodulin expression. Nat Med 2013;19:1655-60.

6. Regele F, Jelencsics K, Shiffman D, Paré G, McQueen MJ, Mann JF, et al. Genome-wide studies to identify risk factors for kidney disease with a focus on patients with diabetes. Nephrol Dial Transplant 2015;30 Suppl 4:iv26-34

7. Köttgen A, Glazer NL, Dehghan A, Hwang SJ, Katz R, Li M, et al. Multiple loci associated with indices of renal function and chronic kidney disease. Nat Genet 2009;41:712-7.

8. Reznichenko A, Böger CA, Snieder H, van den Born J, de Borst MH, Damman J, et al. UMOD as a susceptibility gene for end-stage renal disease. BMC Med Genet 2012;13:78.

9. Bates JM, Raffi HM, Prasadan K, Mascarenhas R, Laszik Z, Maeda N, et al. Tamm-Horsfall protein knockout mice are more prone to urinary tract infection: Rapid communication. Kidney Int 2004;65:791-7.

10. Serafini-Cessi F, Malagolini N, Cavallone D. Tamm-Horsfall glycoprotein: Biology and clinical relevance. Am J Kidney Dis 2003;42:658-76.

11. Köttgen A. Genome-wide association studies in nephrology research. Am J Kidney Dis 2010;56:743-58.

12. Chambers JC, Zhang W, Lord GM, van der Harst P, Lawlor DA Sehmi JS, et al. Genetic loci influencing kidney function and chronic kidney disease. Nat Genet 2010;42:373-5. 